\title{
TOWARDS OPTIMUM DESIGN FOR CRACK WIDTH LIMIT STATES: THE NEED FOR FURTHER DEVELOPMENTS
}

\author{
MIROSLAV SYKORA*, MILAN HOLICKY \& JANA MARKOVA \\ Klokner Institute, Czech Technical University in Prague, Czech Republic
}

\begin{abstract}
Serviceability limit states including cracking are of increasing importance and often dominate the design of reinforced concrete structures. Furthermore, actual crack widths and their shape play an important role in the assessment of service life of existing reinforced concrete structures. Crack width is inherently a random variable of considerable scatter due to randomness of material properties, geometry of the structure, loading and model uncertainty in crack width estimates. The state-of-the-art concepts for serviceability verifications were recently presented in fib Model Code 2010 that is jointly with Eurocode EN 1992-1-1 considered as key background materials in this study. To assess the sufficiency of code requirements and design procedures, crack widths of water retaining structures are investigated in detail using probabilistic methods of structural reliability. The current codes seem to be well calibrated to reach a target reliability index of 1.5 in the serviceability limit states. The two variables dominating structural reliability are uncertainty in crack width model and concrete cover. Numerous topics need to be further investigated including revision of crack width limits, improvements of mechanical models, quantification of model uncertainty, methodology for load combinations, treatment of spatial variability for large structures, and optimisation of target reliabilities.

Keywords: cracking, design, Eurocode, model uncertainty, reinforced concrete, service life, serviceability, water retaining structure.
\end{abstract}

\section{INTRODUCTION}

Cracking of concrete structures is mostly caused by low tensile strength of concrete and the arrangement of reinforcement, its diameter and thickness of concrete cover play also an important role. This phenomenon is reflected by allowing for crack development in structural design. In many structures crack width criteria are not verified and it is sufficient to comply with reinforcement detailing requirements in design standards. However, for special circumstances it may be necessary to specifically include procedures in the design process to limit crack widths. Such conditions may include temperature effects, structural restraint, or the specific purpose of the structure such as concrete water retaining structures.

In special cases therefore, designers need to verify crack widths against specified criteria. Structural design standards provide guidelines for the calculation of crack widths in concrete structures. Criteria for crack widths are then expressed as limiting values depending on performance requirements such as durability, the effectiveness of containment or protection against leakage through wide cracks of slabs in underground garages.

This paper presents a probabilistic evaluation of the crack width calculation for a specific case in the design of concrete water retaining structures. The paper considers the general crack width calculation procedures of EN 1992-1-1:2004 for general rules of design of concrete structures (hereafter "EC2" for brevity) and limits for water retaining structures as specified in EN 1992-3:2006.

\footnotetext{
* ORCID: http://orcid.org/0000-0001-9346-3204
} 


\section{SCOPE OF ANALYSIS}

For probabilistic reliability verification, the following items are investigated hereafter:

- Load combinations to be considered for the analysis of cracking and classification of the hydrostatic pressure.

- Limits to crack width.

Taking into account the principles of Eurocodes and fib MC 2010 [1], and the findings provided in recent studies [2]-[8], the fundamental aspects are discussed further and provisional recommendations are offered.

\subsection{Load combinations}

Cracking is commonly considered as one type of the serviceability limit states ("SLS") analysed using an appropriate combination of actions. In general, the criteria are commonly verified for a quasi-permanent combination of actions defined in EN 1990, EN 1992, and MC 2010. This combination includes primarily permanent actions while the effects of variable actions are:

- Taken into account - imposed loads in storage and industrial areas.

- Significantly reduced - imposed loads in residential and office buildings.

- Disregarded - climatic actions on buildings, traffic loads on bridges.

In accordance with EN 1990:2002 for basis of structural design, water actions may be classified as permanent and/or variable actions depending on the variation of their magnitude with time. Hydrostatic pressure in water retaining structures seems to be almost fixed and its variation with time is negligible. It is therefore justifiable to classify the hydrostatic pressure in water retaining structures as a permanent action. According to EN 1992-3, the quasipermanent combination of actions is used for liquid retaining and containment structures to provide an adequate assurance that cracks do not pass through the full width of a section. Thus, this combination is considered in this study. Holicky et al. [9] emphasised that the hydrostatic pressure should be considered as a permanent load or variable load with a unity combination factor when using the quasi-permanent combination.

\subsection{Limiting crack width}

EN 1990 and EC2 indicate that appropriate limits to crack width should be selected taking into account the required function of the structure. However, it appears that the limits recommended in literature and codes are mostly based on past experience. Newly designed structural reinforced concrete members should comply with the criteria given in EC2 or MC 2010 wherein the crack width limits $w_{\text {lim }}$ range between $0.2-0.4$ for normal structures. More detailed classification is provided in fib Bulletin 62 [10].

EN 1992-3 assumes four non-permeability structural classes. The EN standard recommends for cracks which can be expected to pass through the full thickness of the section the limits ranging from $0.05 \mathrm{~mm}$ to $0.2 \mathrm{~mm}$, depending on a ratio between the thickness and height of hydrostatic pressure of the liquid retaining structure. On the basis of practical experience, the Designers Guide [11] argues that $\leq 0.2 \mathrm{~mm}$ cracks passing through a section tend to leak somewhat initially, but quickly seal themselves. Thus, it appears that the limiting value of $0.2 \mathrm{~mm}$ represents a reasonable requirement for common water retaining structures. The ultimate choice of a value may also depend on structural conditions including special requirements imposed for instance by the application of coating, possible consequences of 
structure malfunctioning, and relative costs of serviceability improvements. The last aspect is particularly important for existing structures where wider crack widths are often acceptable due to higher repair costs or limited required residual working life.

\section{CRACK WIDTH MODEL}

The procedure of crack width estimation provided in MC 2010 and EC2 is based on the physical model introduced in the CEB Design Manual [12]. The crack width $w$ is given as:

$$
w=s_{\mathrm{r}, \mathrm{m}}\left(\varepsilon_{\mathrm{sm}}-\varepsilon_{\mathrm{cm}}\right),
$$

where $s_{\mathrm{r}, \mathrm{m}}=$ mean crack spacing; $\varepsilon_{\mathrm{sm}}=$ mean strain in the reinforcement under the relevant combination of actions; and $\varepsilon_{\mathrm{cm}}=$ mean strain in the concrete between the cracks. The mean crack spacing is given as:

$$
S_{\mathrm{r}, \mathrm{m}}=k_{3} c+k_{1} k_{2} k_{4} \phi / \rho_{\mathrm{p}, \mathrm{eff}},
$$

where $k_{3}=2-$ empirical parameter to take the influence of the concrete cover into consideration; $c=$ concrete cover of reinforcement, $k_{1}=0.8$ - coefficient for high bond bars; $k_{2}=1-$ coefficient for stress distribution in the case with pure tension; $k_{4}=0.25$ - empirical parameter; $\phi=$ bar diameter; and $\rho_{\mathrm{p} \text {,eff }}$ is the effective reinforcement ratio defined in EC2. The variety of mean crack spacing models was provided in [7].

The mean tensile strain is expressed as:

$$
E_{\mathrm{sm}}-\varepsilon_{\mathrm{cm}}=\left[\sigma_{\mathrm{s}}-k_{\mathrm{t}} f_{\mathrm{ct}, \mathrm{eff}}\left(1+\alpha_{\mathrm{e}} \rho_{\mathrm{p}, \mathrm{eff}}\right) / \rho_{\mathrm{p}, \mathrm{eff}}\right] / E_{\mathrm{s}} \geq 0.6 \sigma_{\mathrm{s}} / E_{\mathrm{s}},
$$

where $\sigma_{\mathrm{s}}=$ stress in the tension reinforcement assuming a cracked section; $k_{\mathrm{t}}=0.4$ is the factor for long-term loading; $f_{\text {ct,eff }}=$ mean value of the tensile strength of the concrete effective at the time when first cracks are expected to occur - considered to be equal to the mean value of axial tensile concrete strength $f_{\text {ctm }}$ for the cracks developing after 28 days; and $\alpha_{\mathrm{e}}=$ ratio $E_{\mathrm{s}} / E_{\mathrm{cm}}$ between the modulus of reinforcing steel and concrete.

Verification of the limit state of crack width is based on the following inequality:

$$
w_{\mathrm{k}} \leq w_{\lim },
$$

where $w_{\mathrm{k}}=$ characteristic crack width obtained as $95 \%$ fractile of probabilistic distribution of crack width [11]. According to EC2, the characteristic crack width is obtained from eqns (1)-(3) by increasing the coefficients $k_{3}$ and $k_{4}$ to 3.4 and 0.425 , respectively.

\section{NUMERICAL EXAMPLE}

\subsection{Partial factor method}

Following Holicky et al. [9], the configuration of a representative water retaining structure is considered as follows:

- Cylindrical reservoir with a diameter $\mathrm{D}=28 \mathrm{~m}$ and height of $7 \mathrm{~m}$; wall thickness of $250 \mathrm{~mm}$.

- Concrete class C25/30; reinforcement bar diameter of $20 \mathrm{~mm}$.

The action effect of tensile hoop stress is directly related to the hydrostatic pressure of the water. Its characteristic value is assumed to correspond to a mean pressure and partial factor $\gamma=1.2$ is applied as recommended in EN 1992-3:

- The maximum water pressure: $\mathrm{Lk}=70 \mathrm{kN} / \mathrm{m}^{2}$. 
- The characteristic force in the wall: $\mathrm{Nk}=\mathrm{D} \mathrm{Lk} / 2=980 \mathrm{kN}$.

- Design value of the force: $\mathrm{Nd}=\gamma \mathrm{Nk}=1176 \mathrm{kN}$.

All the values are per meter of width of the cross section. The combination with thermal, shrinkage, and creep actions is beyond the scope of the present investigation; the effects of creep are taken into account through coefficient $\varphi$; see Section 4.2. Reinforcement area $A_{\mathrm{s}}=0.005 \mathrm{~m}^{2} / \mathrm{m}$ is needed to meet the requirement $w_{\mathrm{k}}=w_{\lim }=0.2 \mathrm{~mm}$ when applying the increased coefficients $k_{3}$ and $k_{4}$, and $\gamma=1.2$.

\subsection{Probabilistic verification}

Probabilistic methods are applied to verify reliability of the reservoir designed according to Eurocodes with respect to the SLS of crack width. The limit state function $\mathrm{g}($.$) is expressed$ in terms of the limit value of the crack width $w_{\text {lim }}$ and the random crack width $w($.$) :$

$$
\mathrm{g}(\mathbf{X}, t)=w_{\lim }-\theta w(\mathbf{X}, t),
$$

where $\mathbf{X}=$ vector of basic variables; $\theta=$ model uncertainty in crack width estimate; $t=$ time. The crack width $w($.$) is obtained from eqn (1). Failure probability p_{\mathrm{f}}$ of a random crack width exceeding the crack width limit $w_{\text {lim }}$ is:

$$
p_{\mathrm{f}}(\mathbf{X}, t)=\mathrm{P}\left[w_{\lim }-\theta w(\mathbf{X}, t)<0\right] .
$$

The reservoir is considered reliable if the following inequality is satisfied:

$$
P_{\mathrm{f}}(\mathbf{X}, t) \leq p_{\mathrm{t}},
$$

where $p_{\mathrm{t}}=$ specified (target) value that should not be exceeded during the working life. The reliability criterion (7) can be equivalently expressed in terms of the generalized reliability index $\beta$ obtained from failure probability as a negative value of the inverse cumulative distribution function of standardised normal variable, EN 1990:

$$
\beta(\mathbf{X}, t) \geq \beta_{\mathrm{t}} .
$$

The probabilistic models of random variables are provided in Table 1. Several basic variables entering the limit state function (5) are assumed to be deterministic - most of geometric characteristics, steel modulus of elasticity, and the $k$-parameters of the crack width model.

Table 1: Probabilistic models of basic variables.

\begin{tabular}{|l|c|c|c|c|c|c|}
\hline Variable & Symbol & Distribution & Unit & $\begin{array}{c}\text { Mean } \\
\mu\end{array}$ & $\begin{array}{c}\text { Coeff. of } \\
\text { var. } V\end{array}$ & References \\
\hline $\begin{array}{l}\text { Concrete tensile } \\
\text { strength }\end{array}$ & $f_{\mathrm{ct}}$ & Lognormal & $\mathrm{MPa}$ & 2.2 & 0.3 & {$[16],[17]$} \\
\hline $\begin{array}{l}\text { Modulus of elasticity }- \\
\text { concrete }\end{array}$ & $E_{\mathrm{c}}{ }^{(\mathrm{a})}$ & Lognormal & $\mathrm{GPa}$ & 30 & 0.15 & $\begin{array}{c}\mathrm{EC} 2, \\
{[16],[17]}\end{array}$ \\
\hline Creep coefficient & $\varphi$ & Lognormal & - & $2.6^{(\mathrm{b})}$ & 0.2 & $\mathrm{EC} 2,[18]$ \\
\hline Concrete cover & $C$ & Beta $^{(\mathrm{c})}$ & $\mathrm{mm}$ & 40 & 0.25 & {$[16]$} \\
\hline Liquid pressure & $L$ & Normal & $\mathrm{kN} / \mathrm{m}^{2}$ & 70 & 0.05 & {$[9]$} \\
\hline $\begin{array}{l}\text { Crack width model } \\
\text { uncertainty }\end{array}$ & $\theta$ & Lognormal & - & 0.9 & 0.3 & {$[3]$} \\
\hline
\end{tabular}

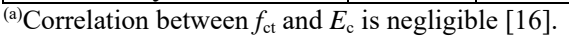

(b) The mean value estimated for a reference period of 50 years using EC2.

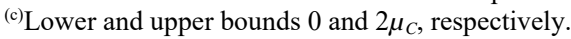


Model uncertainty $\theta$ is considered as an auxiliary random variable to account for the effects that are ignored or insufficiently captured by the crack width model, including uncertainty related to the $k$-parameters. Focusing on the EC2 model, a few previous studies provided indications on model uncertainty characteristics:

- McLeod et al. [3] compared model predictions and test results for members in pure tension and obtained:

o A mean value $\mu_{\theta}=0.86$ and coefficient of variation $V_{\theta}=0.23$ for short-term tension loading (sample size $n=65$ ).

o $\mu_{\theta}=0.90$ and $V_{\theta}=0.30$ for long-term loading $(n=25)$.

- The same authors [2] investigated flexural crack widths:

o $\mu_{\theta}=1.16$ and $V_{\theta}=0.51$ for short-term loading $(n=620)-$ note that Cervenka et al. [5] obtained $\mu_{\theta}=1.1$ and $V_{\theta}=0.35$ for short-term flexural crack widths predicted by FEM.

$0 \mu_{\theta}=1.42$ and $V_{\theta}=0.34$ for long-term loading $(n=50)$.

- Markova and Sykora [6] assumed $\mu \theta=1$ and $\mathrm{V} \theta=0.3$ for flexural cracks under longterm loading, based on the observations in [11], [13]-[15].

The model uncertainty characteristics provided by McLeod et al. [3] for long-term tension are adopted in reliability analysis.

Further research is obviously needed to obtain representative model uncertainty characteristics. It should be based on a large test database and detailed comparison of test and model outcomes. The methodology of model uncertainty quantification was proposed by Holicky et al. [19] and applied in the pilot investigations by Sykora et al. [20], [21].

The SORM analysis leads to reliability index $\beta=1.7$ that needs to be compared with an appropriate target reliability level. Serviceability failure does not lead to a structural collapse, but may affect its functionality. This is obviously reflected in the target reliability levels recommended by codes that are below the levels recommended for the ultimate limit states.

Table 2 provides the overview of target reliability levels for SLS in various documents. Note that lower target levels for SLSs may lead to underestimating relevance of serviceability verifications of concrete structures in practice. This is confirmed by numerous forensic cases of inadequate or erroneous design. Recent examples include leakages through cracks in underground slabs, large deflections of floors in buildings and of bridges during medium to long time periods.

Table 2: Overview of target reliability levels for SLS in various documents.

\begin{tabular}{|c|c|c|c|}
\hline $\begin{array}{l}\text { Relative effort } \\
\text { to achieve } \\
\text { serviceability } \\
\end{array}$ & Annual $\beta$ & Lifetime $\beta$ & Source, note \\
\hline High & 1.3 & - & \multirow{3}{*}{$\begin{array}{l}\text { JCSS PMC [16] and Rackwitz } \\
\text { [22]. The former additionally } \\
\text { notes that the target levels are } \\
\text { associated with irreversible SLSs }\end{array}$} \\
\hline Normal & 1.7 & - & \\
\hline Low & 2.3 & - & \\
\hline Not considered & 2.9 & 1.5 & EN 1990; irreversible SLS \\
\hline Not considered & $\begin{array}{c}3.0- \\
\text { irreversible } \\
\text { (design) }\end{array}$ & $\begin{array}{c}0 \text { - reversible } \\
\text { (design); } 1.5 \\
\text { (existing) }\end{array}$ & fib MC 2010 [1] \\
\hline $\begin{array}{l}\text { Parametric } \\
\text { study }\end{array}$ & \multicolumn{2}{|c|}{$\begin{array}{c}0-3.7 ; 1.5 \text { found as a } \\
\text { representative value (reference } \\
\text { period not indicated) }\end{array}$} & $\begin{array}{l}\text { Van Nierop et al. [4]- cost } \\
\text { optimisation }\end{array}$ \\
\hline
\end{tabular}


In the case study, reliability of the reservoir is nearly ideally time-invariant and thus the design target levels might be considered in a range from 1.3-3.0. Holicky et al. [9] suggested verifying the requirements for crack widths and their reliability using methods of probabilistic optimization, to balance cost of measures used for increasing the reliability level and cost of expected consequences due to an infringement of the required crack width limits. Possible measures to increase reliability may include enhancement of reinforcement area, surface treatment of the reservoir wall and other possible actions. Consequences of crack limits infringement may include leakage of the reservoir and possible requirement for its repair that may further induce other unfavourable situations. Van Nierop et al. [4] found a value of 1.5 to be representative. This is considered hereafter as a reference level; the amount of reinforcement obtained by the partial factor method thus seems to lead to a reasonable reliability level. Further discussion of the controversial topic of the target reliability for SLSs is beyond the scope of this study.

\subsection{Sensitivity analysis}

Sensitivity analysis reveals that the two variables dominating structural reliability are model uncertainty and concrete cover whose sensitivity factors are -0.84 and -0.47 , respectively. The significant effect of model uncertainty on predicted $\beta$-values is demonstrated by increasing $V_{\theta}$ to 0.4 following the assumptions related to the EC2 model [11] - reliability index decreases below the target level, $\beta=1$.4. Similarly, reliability index drops to 1.3 when the bias in model predictions is ignored $\left(\mu_{\theta}=1.0\right)$.

Fig. 1 displays the variation of reliability index with the mean (nominal) value of concrete cover $\mu_{C}$ for various model uncertainty characteristics. For each $\mu_{C}$, reinforcement area is adjusted to meet the requirement of $0.2 \mathrm{~mm}$ using the partial factor method. It appears that the reliability level is quite insensitive to changes of $\mu_{C}$ while both mean and coefficient of variation of the model uncertainty affect the predicted reliability levels.

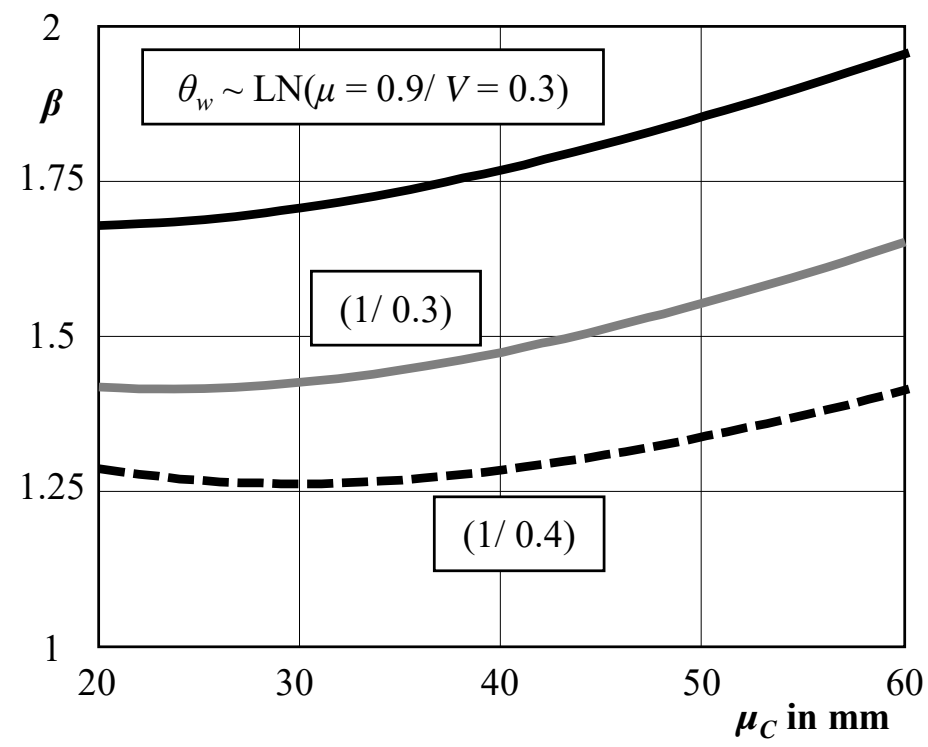

Figure 1: Variation of reliability index with the mean (nominal) value of concrete cover for $\mathrm{C} 20 / 25$ and wlim $=0.2 \mathrm{~mm}$. 
To provide further insights into SLS reliability levels for various design configurations, some of the probabilistic models of random variables given in Table 1 and geometrical characteristics are modified as follows:

- Reinforcement bar diameter $\varnothing$ varies from $10-30 \mathrm{~mm}$ while $\mu \mathrm{C}=40 \mathrm{~mm}$ is constant.

- In addition to $\mathrm{C} 20 / 25$, a concrete class $\mathrm{C} 30 / 37$ - often used for mixes with reduced heat of hydration [9] - is considered with modified mean values: $\mu \mathrm{fct}=2.9 \mathrm{MPa}$, $\mu \mathrm{Ec}=32.8 \mathrm{MPa}$, and $\mu \varphi=2.2$.

- In addition to wlim $=0.2 \mathrm{~mm}$, a widely adopted limit of $0.3 \mathrm{~mm}$ is taken into account for illustrative purposes.

For each design configuration, the reinforcement area is again adjusted to comply with $w_{\text {lim }}$ by the partial factor method.

The decreasing reliability index with increasing reinforcement bar diameter shown in Fig. 2 suggests that the effect of $\varnothing$ on crack widths is insufficiently considered in the EC2 model. The model should be developed and carefully validated. Fig. 2 further indicates that similar reliability levels are obtained for both concrete classes under consideration.

Interesting is that obtained reliability is also influenced by applied $w_{\lim }$. This might be seen as the deficiency of the EC2 method, indicating too optimistic decrease in reinforcement area when the limit is less strict $(0.3 \mathrm{~mm})$. However, careful interpretation is needed here as the reliability indices in Fig. 2 are based on the simplified assumption that model uncertainty is independent of crack width. The detailed investigations of several tests [23] indicated that the coefficient of variation of model uncertainty may somewhat decrease with an increasing crack width (for $0.2 \mathrm{~mm} \leq w \leq 1 \mathrm{~mm}$ ). This would reduce the difference between the reliability levels for $w_{\lim }=0.2$ and $0.3 \mathrm{~mm}$ in Fig. 2 .

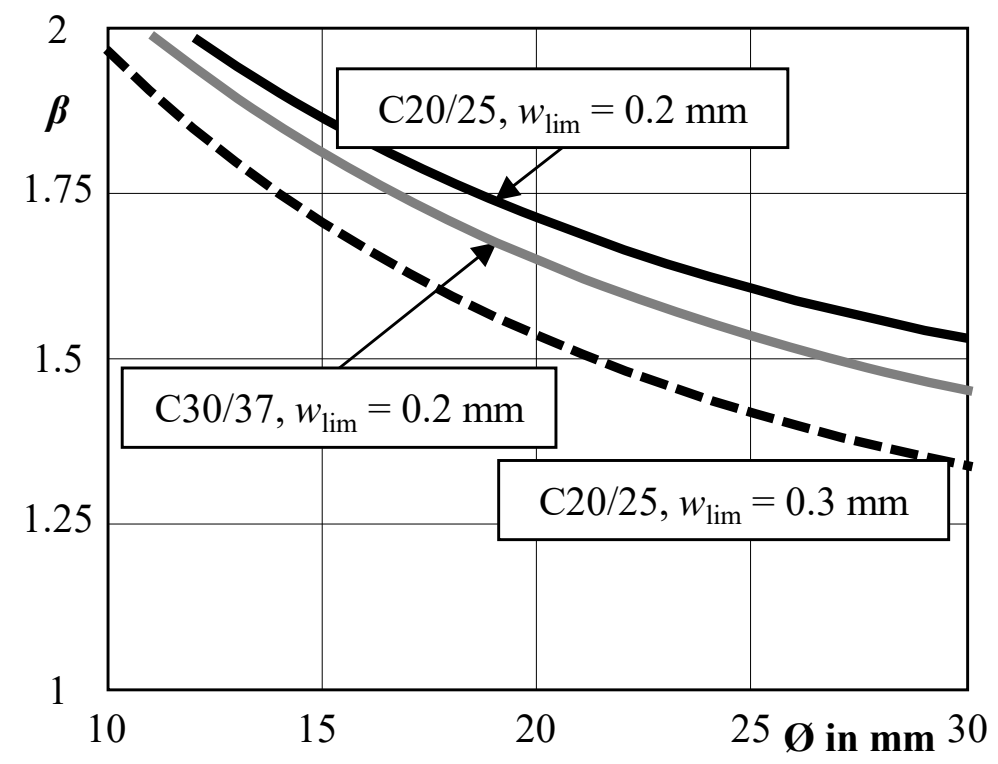

Figure 2: Variation of reliability index with reinforcement bar diameter $(\mu \mathrm{C}=40 \mathrm{~mm}$, $\mu \theta=0.9$, and $\mathrm{V} \theta=0.3$ ) for two concrete classes $\mathrm{C} 20 / 25$ and $\mathrm{C} 30 / 37$. 


\section{DISCUSSION}

\subsection{FEM predictions}

As the interaction between concrete and reinforcing bars represents a rather complex problem, the engineering formulae such as those recommended in EC2 and MC 2010 are approximate. An improvement of models is expected by employing an advanced modelling of cracking with numerical simulations based on the finite element method. The FEM analysis can take into account more realistic stress distribution for given structural geometry and also time-dependent effects of initial strain development due to temperature, shrinkage, and creep. Consequently, unbiased estimates of crack widths are obtained and dispersion of model uncertainty reduces [5]. To indicate the scope of application of engineering and FEM approaches and reach the balance between model and input parameter uncertainties, the analysis of their model uncertainties and sensitivity analysis with respect to effects of basic variables is needed.

\subsection{Spatial variability}

The magnitude of the reliability levels obtained in this study needs to be considered as indicative only since the spatial variability of basic variables - particularly of concrete tensile strength, concrete modulus of elasticity, and of concrete cover - is ignored. In probabilistic analyses the spatial variability is normally described by random fields; JCSS [16] along with experimental results published in literature provides some background for random field modelling. Application of discretisation techniques and subsequent analysis of random fields may be rather cumbersome, particularly in the case of optimisation and parametric studies. Hence a simplified probabilistic model for spatial variability was developed in [24] to make it possible to analyse large structures by efficient reliability methods such as FORM/SORM. This model is expected to be used in further optimisation studies.

\subsection{Outline of further research}

While probabilistic optimisation can assist to develop suitable design formats for crack width control, the following research activities, based on this study along with broader experience of the authors with reliability analyses concerning crack widths, are needed:

1. Revising limiting values considering the reasons for crack width control.

2. Improving mechanical models for crack widths predictions so as to achieve balanced reliability for structures under pure tension or flexure, subjected to short- or long-term loading.

3. Estimating model uncertainty characteristics for crack width predicting based on comparison of test and model outcomes and analysing trends of model uncertainty characteristics with basic variables.

4. Providing recommendations on the scope of application of engineering and FEM approaches in order to reach the balance between model and input parameter uncertainties.

5. Developing methodology of reliability verification with respect to crack widths under variable actions such as imposed loads, considering different purposes of crack width control.

6. Specifying how the spatial variability of basic variables should be taken into account for large structures. 
7. Optimising target reliabilities considering costs of increasing serviceability and failure consequences; the distinction between structural design and assessment of existing structures should be made.

\section{CONCLUSIONS}

The presented reliability analysis of a reinforced concrete water reservoir with respect to crack width reveals that:

- The partial factor design of concrete retaining structures according to Eurocodes meets serviceability requirements and leads to reliability indices around 1.5 for various concrete classes.

- Non-uniform reliability levels are obtained for various diameters of reinforcing bars.

- Two sources of uncertainties dominating structural reliability consist of crack width model and concrete cover.

- The theoretical procedures of probabilistic optimisation can assist to develop suitable design formats for crack width control.

\section{ACKNOWLEDGEMENT}

This work was supported by the Czech Science Foundation under Grants 16-04132S and $16-11378 \mathrm{~S}$.

\section{REFERENCES}

[1] fib Model Code for Concrete Structures 2010, fib: Lausanne, 402 pp., 2013.

[2] McLeod, C., Barnardo-Vijloen, C. \& Retief, J.V., Determining model uncertainty associated with concrete crack models in flexure. Proceedings of the 15th International Probabilistic Workshop, eds M. Voight, D. Proske, W. Graf, M. Beer, U. Häussler-Combe \& P. Voight, TUDpress: Dresden, pp. 261-270, 2017.

[3] McLeod, C., Barnardo-Vijloen, C. \& Retief, J.V., Determining model uncertainty associated with concrete crack models in tension. Proceedings of the 15th International Probabilistic Workshop, eds M. Voight, D. Proske, W. Graf, M. Beer, U. Häussler-Combe \& P. Voight, TUDpress: Dresden, pp. 271-282, 2017.

[4] Van Nierop, S., Viljoen, C. \& Lenner, R., Target reliability of concrete structures governed by serviceability limit state design. Proceedings of the 15th International Probabilistic Workshop, eds M. Voight, D. Proske, W. Graf, M. Beer, U. HäusslerCombe \& P. Voight, TUDpress: Dresden, pp. 293-302, 2017.

[5] Cervenka, V., Markova, J., Mlcoch, J., Caldentey, A.P., Sajdlova, T. \& Sykora, M., Uncertainties of crack width models. High Tech Concrete: Where Technology and Engineering Meet - Proceedings of the 2017 fib Symposium, eds M. Lukovic \& D.A. Hordijk, Springer International Publishing: pp. 1653-1661, 2017.

[6] Markova, J. \& Sykora, M., Uncertainties in crack width verification of reinforced concrete structures. Proceedings of ESREL 2016, eds L. Walls, M. Revie \& T. Bedford, Taylor and Francis/Balkema: Leiden, pp. 2433-2438, 2017.

[7] Borosnyói, A. \& Balázs, G.L., Models for flexural cracking in concrete: The state of the art. Structural Concrete, 6(2), pp. 53-62, 2005. DOI: 10.1680/stco.6.2.53.66711.

[8] Balázs, G.L. et al., Design for SLS according to fib Model Code 2010. Structural Concrete, 14(2), pp. 99-123, 2013. DOI: 10.1002/suco.201200060.

[9] Holicky, M., Retief, J.V. \& Wium, J., Probabilistic design for cracking of concrete structures. Proceedings of the 7th International Probabilistic Workshop, eds J.K. Vrijling, P. van Gelder \& D. Proske, TU Delft: Delft, pp. 87-98, 2009. 
[10] fib, Bulletin 62 - Structural Concrete Textbook on Behaviour, Design and Performance, 2nd ed., Vol. 5: Through-life Care and Management of Concrete Structures - Assessment, Protection, Repair and Strengthening, fib: Lausanne, 476 pp., 2012.

[11] Narayanan, R.S. \& Beeby, A., Designers' Guide to EN 1992-1-1 and EN 1992-1-2 Eurocode 2: Design of Concrete Structures. General Rules and Rules for Buildings and Structural Fire Design, Thomas Telford Ltd: 232 pp., 2005.

[12] CEB, CEB Design Manual on Cracking and Deformations, École polytechnique fédérale de Lausanne: Lausanne, 1985.

[13] Markova, J. \& Holicky, M., Probabilistic assessment of crack width for existing bridges. Proceedings of ESREL 2009, CRC Press/Balkema: Leiden, pp. 1431-1435, 2009.

[14] Braam, C.R., Control of crack width in deep reinforced concrete beams. Heron, 35(4), pp. 1-106, 1990.

[15] Allam, S.M., Shoukry, M.S., Rashad, G.E. \& Hassan, A.S., Crack width evaluation for flexural RC members. Alexandria Engineering Journal, 51(3), pp. 211-220, 2012. DOI: http://dx.doi.org/10.1016/j.aej.2012.05.001.

[16] JCSS, JCSS Probabilistic Model Code (periodically updated, online publication), Joint Committee on Structural Safety, 2018.

[17] fib, Code-type Models for Concrete Behaviour (Background of MC2010, bulletin 70), fib: Lausanne, 190 pp., 2013.

[18] Vrouwenvelder, A.C.W.M. \& Siemes, A.J.M., Probabilistic calibration procedure for the derivation of partial safety factors for the Netherlands building codes. Heron, 32(4), pp. 9-29, 1987.

[19] Holicky, M., Sykora, M. \& Retief, J.V., Assessment of model uncertainties for structural resistance. Probabilistic Engineering Mechanics, 45, pp. 188-197, 2016. DOI: 10.1016/j.probengmech.2015.09.008.

[20] Sykora, M., Holicky, M., Prieto, M. \& Tanner, P., Uncertainties in resistance models for sound and corrosion-damaged RC structures according to EN 1992-1-1. Materials and Structures, 48(10), pp. 3415-3430, 2015. DOI: 10.1617/s11527-014-0409-1.

[21] Sykora, M., Krejsa, J., Mlcoch, J., Prieto, M. \& Tanner, P., Uncertainty in shear resistance models of reinforced concrete beams according to fib MC2010 (in press). Structural Concrete, pp. 1-12, 2018. DOI: 10.1002/suco.201700169.

[22] Rackwitz, R., Optimization - the basis of code-making and reliability verification. Structural Safety, 22(1), pp. 27-60, 2000. DOI: http://dx.doi.org/10.1016/S0167-4730 (99)00037-5.

[23] Mlcoch, J., Markova, J. \& Sykora, M., Uncertainty in crack width estimates according to fib Model Code 2010. Transactions of the VSB - Technical University of Ostrava, Civil Engineering Series, 17(1), pp. 155-158, 2017. DOI: 10.1515/tvsb-2017-0018.

[24] Sykora, M. \& Holicky, M., Durability assessment of large surfaces. Proceedings of ICOSSAR 2013, eds G. Deodatis, B.R. Ellingwood \& D.M. Frangopol, CRC Press/Balkema: Leiden, pp. 2665-2671, 2013. 